\title{
CD20 Antigen Status
}

National Cancer Institute

\section{Source}

National Cancer Institute. CD20 Antigen Status. NCI Thesaurus. Code C74095.

Determination of presence or absence of CD20 antigen. 